\title{
Inhibition of Mitogen-Activated Protein Kinase Kinase Alone and in Combination with Anaplastic Lymphoma Kinase (ALK) Inhibition Suppresses Tumor Growth in a Mouse Model of ALK-Positive Lung Cancer
}

\author{
N. Shrestha, A.R. Bland, R.L. Bower, R.J. Rosengren, and J.C. Ashton \\ Department of Pharmacology and Toxicology, School of Biomedical Sciences, University of Otago, Dunedin, New Zealand \\ Received March 1, 2020; accepted April 8, 2020
}

\begin{abstract}
Anaplastic lymphoma kinase (ALK)-positive non-small-cell lung cancer most commonly arises through EML4 (Echinoderm Microtuble Like 4)-ALK chromosomal fusion. We have previously demonstrated that combination of the ALK inhibitor crizotinib with the MEK inhibitor selumetinib was highly effective at reducing cell viability of ALK-positive non-small-cell lung cancer (H3122) cells. In this study, we further investigated the efficacy of crizotinib and selumetinib combination therapy in an in vivo xenograft model of ALK-positive lung cancer. Crizotinib decreased tumor volume by $52 \%$ compared with control, and the drug combination reduced tumor growth compared with crizotinib. In addition, MEK inhibition alone reduced tumor growth by $59 \%$ compared with control. Crizotinib and selumetinib alone and in combination were
\end{abstract}

nontoxic at the dose of $25 \mathrm{mg} / \mathrm{kg}$, with values for $\mathrm{ALT}(<80 \mathrm{U} / \mathrm{l})$ and creatinine $(<2 \mathrm{mg} / \mathrm{dl})$ within the normal range. Our results support the combined use of crizotinib with selumetinib in ALK-positive lung cancer but raise the possibility that a sufficient dose of an MEK inhibitor alone may be as effective as adding an MEK inhibitor to an ALK inhibitor.

\section{SIGNIFICANCE STATEMENT}

This study contains in vivo evidence supporting the use of combination MEK inhibitors in ALK+ lung cancer research, both singularly and in combination with ALK inhibitors. Contrary to previously published reports, our results suggest that it is possible to gain much of the benefit from combination treatment with an MEK inhibitor alone, at a tolerable dose.

\section{Introduction}

Non-small-cell lung cancer (NSCLC) is the leading cause of cancer death worldwide, accounting for approximately 80\%-85\% of lung cancer cases (Ettinger et al., 2013; Ferlay et al., 2015). Anaplastic lymphoma kinase (ALK) gene rearrangements are found in $2 \%-7 \%$ of NSCLC, in which they are key oncogenic drivers that promote cancer cell proliferation and survival through activation of intracellular signaling pathways (Soda et al., 2007; Perner et al., 2008; Roskoski, 2013).

Crizotinib is a first-generation ALK tyrosine kinase inhibitor approved by the Food and Drug Administration and the European Medicines Agency for the treatment of ALKpositive NSCLC (Kwak et al., 2010; Camidge et al., 2012; Kazandjian et al., 2014). Based on a phase I dose escalation study, the maximum tolerated dose for crizotinib is $250 \mathrm{mg}$ by mouth twice daily (Kwak et al., 2009, 2010). Treatmentrelated adverse events are mostly grade 1 or 2 , such as

This work was supported by a University of Otago Research Grant (Grant 0119-0520)

https://doi.org/10.1124/jpet.120.266049.

S This article has supplemental material available at jpet.aspetjournals.org. gastrointestinal upset, visual disturbances, and peripheral edema. Grade 3 or 4 adverse events, including neutropenia, raised alanine aminotransferase (ALT) enzymes, lymphopenia, and pneumonitis, were observed in a minority of patients (Camidge et al., 2012).

In subsequent trials, ALK-positive patients with NSCLC were highly responsive to crizotinib, with an objective response rate of $74 \%$ and progression-free survival of 10.9 months compared with standard chemotherapy, which has an objective response rate of $45 \%$ and progression-free survival of 7 months (Solomon et al., 2014). However, the majority of patients develop resistance typically within 12 months of beginning therapy. Mechanisms of resistance include ALK gene alterations such as ALK point mutation or copy number gain and activation of bypass signaling via the activation of other oncogenes, such as insulin-like growth factor-1 receptor, epidermal growth factor receptor, human epidermal growth factor receptor 2 and cKIT (CD117), or mutations in epidermal growth factor receptor or kirsten rat sarcoma (Choi et al., 2010; Sasaki et al., 2011; Zhang et al., 2011; Doebele et al., 2012; Katayama et al., 2012). Although newgeneration ALK inhibitors such as alectinib and ceritinib have extended survival times, new therapeutic strategies that overcome resistance are needed.

ABBREVIATIONS: ALK, anaplastic lymphoma kinase; ALT, aminotransferase; DAB, 3,3-diaminobenzidine tetrahydrochloride; MEK, mitogenactivated protein kinase kinase; MVD, microvessel density; NSCLC, non-small-cell lung cancer; TUNEL, terminal deoxynucleotidyl transferasemediated digoxigenin-deoxyuridine nick-end labeling. 
Previously, we have demonstrated that combination of crizotinib and selumetinib strongly inhibited the growth of ALK-positive NSCLC cells. This resulted from a reduction in mitogen-activated protein kinase (MAPK) signaling that in turn decreased cell proliferation and increased apoptosis via increased expression of apoptotic markers Bcl-2-like protein 11, cleaved caspase, cleaved poly(ADP-ribose) polymerase, and the cyclin-dependent kinase inhibitor p27 and decreased expression of the cell proliferation marker cyclin D1 (Shrestha et al., 2019). These results supported the finding of Hrustanovic et al. (2015), who found that dual inhibition of ALK/MEK delayed the emergence of drugresistant, ALK-positive NSCLC cell growth compared with the single-drug treatment.

In this study, we investigated the efficacy of crizotinib and selumetinib combination treatment in an in vivo model of ALK-positive NSCLC. We found that both drugs, either alone or in combination, significantly decreased tumor growth compared with control. The combination of crizotinib and selumetinib significantly reduced tumor volume compared with all other treatments, but unexpectedly, selumetinib alone was almost as effective as the two drugs combined. We also investigated the toxicity of crizotinib and selumetinib in $\mathrm{BALB} / \mathrm{c}$ mice. We found no evidence of toxicity from the drugs either singularly or in combination. Body and organ weights were unchanged, and plasma markers for liver and kidney injury were within the normal range. Lastly, we examined whether crizotinib, selumetinib, or the combination could modulate the catalytic activity of hepatic CYP3A, as both drugs are substrates for the cytochrome P450 isoform CYP3A (Mao et al., 2013; Johnson et al., 2015). However, we did not detect an effect on hepatic microsomal CYP3A catalytic activity, suggesting that the two drugs do not cause competitive inhibition of each other's metabolism in vivo. Our findings not only support clinical investigation of crizotinib and selumetinib combination therapy in ALK-positive NSCLC but also suggest that much of the benefit of combination treatment may be gained by the use of MEK inhibitors as a monotherapy.

\section{Methods and Materials}

Materials. The human adenocarcinoma ALK-positive non-smallcell lung cancer (H3122) cell line harboring the EML4-ALK variant 1 fusion gene was kindly gifted from Professor Daniel Costa, Harvard University. Selumetinib and crizotinib were purchased from LC laboratories (Woburn, MA). RPMI, bovine serum albumin, FBS, and penicillin/streptomycin were purchased from Life Technologies. 3,3Diaminobenzidine tetrahydrochloride (DAB) substrate kit and streptavidin-horseradish peroxidase were purchased from BD Biosciences (San Diego, CA). Hematoxylin quick stain (modified Mayer's formula) and avidin-biotin blocking kit were purchased from Vector Laboratories (Burlingame, CA). Hydrogen peroxide (30\%) and ApopTag peroxidase in situ apoptosis detection kit were obtained from Merck (Billerica, MA). Alanine ALT assay kit and Cryomatrix were purchased from Thermo Fisher Scientific (Waltham, MA). Creatinine colorimetric assay kit was purchased from Cayman Chemical Company (Ann Arbor, MI). Matrigel was purchased from Sigma Aldrich (St. Louis, MO). Ki67 was purchased from Abcam (Cambridge, UK). CD105 was obtained from antibodies-online.com (Limerick). CYP3A and glyceraldehyde-3-phosphate dehydrogenase antibody were purchased from Thermo Fisher Scientific. Polyclonal goat anti-rabbit immunoglobulin/biotinylated were purchased from Dako, Denmark.
Animal Housing and Care. Male nude $(\mathrm{Nu} / \mathrm{J})$ mice were purchased from Animal Resource Centre, Australia. Male BALB/c mice were purchased from the Hercus-Taieri Resource Unit, Dunedin, New Zealand. Mice were housed in pathogen-free conditions and supplied with free access to sterile water and food (Reliance rodent diet). The room was maintained at a temperature of $21-24^{\circ} \mathrm{C}$ on a scheduled 12-hour light/dark cycle, and mice were acclimatized for 4 days prior to experiment. All animal experiments were approved by the University of Otago Animal Ethics Committee (AEC Approval No. 18-21 and 18-82).

Drug Efficacy in a Xenograft Model of Lung Cancer. An ALK-positive NSCLC xenograft model was established by subcutaneous injection of H3122 cells $\left(2 \times 10^{6}\right.$ cells in $50 \mu \mathrm{l}$ Matrigel and $50 \mu \mathrm{l}$ of media) in the flank region of $\mathrm{Nu} / \mathrm{J}$ mice. Once the tumor volume had reached $\sim 100 \mathrm{~mm}^{3}$, the mice were randomized into four groups $(n=7)$. Each group received either vehicle ( $25 \% \mathrm{DMSO} / 75 \%$ olive oil, $5 \mathrm{ml} / \mathrm{kg}$ ), crizotinib ( $25 \mathrm{mg} / \mathrm{kg})$, selumetinib $(25 \mathrm{mg} / \mathrm{kg})$, or their combination by mouth once daily for 2 weeks. The doses were chosen on the basis that it is equivalent to a well tolerated human dose (Zhou et al., 2012; Nencioni et al., 2014). Body weight and tumor volume were measured daily. Tumor volume (cubic millimeter) was calculated by multiplying length $\times$ height $\times$ width. At the end of treatment, mice were euthanized by carbon dioxide inhalation, and full necropsies were performed.

Immunohistochemistry. Tumors were fixed in $4 \%$ paraformaldehyde, embedded in Cryomatrix, and sectioned $(6 \mu \mathrm{m})$. The sections were fixed with acetone, and endogenous peroxidase activity was blocked with $3 \%$ hydrogen peroxide for 20 minutes. Heat-mediated antigen retrieval was performed by incubating sections in $0.01 \mathrm{M}$ citrate buffer ( $\mathrm{pH} \mathrm{6)}$. Sections were then incubated with blocking buffer (normal goat serum, bovine serum albumin, avidin) for 1 hour, followed by overnight incubation with primary antibody (CD105 1: 100, Ki67 1:100 along with biotin) at $4^{\circ} \mathrm{C}$. For negative controls, antibody was replaced with PBS. Sections were incubated with biotinylated secondary antibody for 30 minutes, and signal was detected using DAB. Sections were counterstained with hematoxylin, dehydrated, and mounted. Slides were then scanned with Aperio Image ScanScope System (Leica, Chicago, IL). The nuclear image analysis algorithm was used to quantify Ki67-stained (proliferative) cells. The microvessel analysis algorithm was used to quantify the microvessel density (MVD) at a dark- and light-staining threshold of 180 and 210 , respectively.

The TUNEL assay was performed to visualize apoptotic cells using ApopTag in situ detection kit per the manufacturer's instruction. Briefly, sections were fixed in ethanol-acetic acid solution (2:1) and incubated with $3 \%$ hydrogen peroxide. Sections were then incubated with equilibrating buffer followed by terminal deoxynucleotidyl transferase enzyme. For negative control, terminal deoxynucleotidyl transferase enzyme was replaced with PBS. The reaction was stopped using stop/wash buffer and incubated with antidigoxigenin peroxidase. The sections were stained with DAB, counterstained with hematoxylin, dehydrated, and mounted. Slides were then scanned with Aperio Image ScanScope System (Leica). The nuclear image analysis algorithm was used to quantify TUNEL-stained (apoptotic) cells.

Preclinical Toxicity Study. Male BALB/c mice were randomly divided into four groups, with each group containing six mice, except crizotinib $(n=5)$ and combination $(n=7)$. Mice from each group received either vehicle ( $25 \% \mathrm{DMSO} / 75 \%$ olive oil, $5 \mathrm{ml} / \mathrm{kg})$, crizotinib (25 mg/kg), selumetinib ( $25 \mathrm{mg} / \mathrm{kg}$ ), or their combination by mouth once daily for 2 weeks. For positive control of CYP3A assay, mice $(n=$ 5 ) were orally administered daily with dexamethasone $(50 \mathrm{mg} / \mathrm{kg})$ for 4 days. At the end of treatment, mice were euthanized by carbon dioxide inhalation, and full necropsies were performed. Plasma was used to measure ALT activity and creatinine levels as markers for liver and kidney injury, respectively.

Erythromycin $\boldsymbol{N}$-Demethylation. Hepatic microsomes were prepared from treated mice as previously described (Guengerich, 2014). The erythromycin $N$-demethylation assay was then performed 
TABLE 1

Body weight and organ weight of $\mathrm{Nu} / \mathrm{J}$ mice

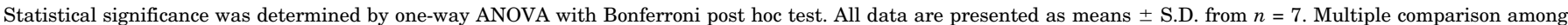
treatment groups and vehicle did not show significant difference in both body and organ weight $(P>0.05)$.

\begin{tabular}{|c|c|c|c|c|}
\hline & Vehicle & Crizotinib (25 mg/kg) & Selumetinib (25 mg/kg) & Crizotinib + Selumetinib \\
\hline Body weight change (g) & $-0.2 \pm 0.77$ & $-0.45 \pm 1.00$ & $-0.4 \pm 0.90$ & $-0.03 \pm 1.25$ \\
\hline \multicolumn{5}{|l|}{ Organ weight (\% of body weight) } \\
\hline Liver & $6.05 \pm 1.09$ & $5.8 \pm 0.56$ & $6.2 \pm 0.76$ & $6.5 \pm 0.38$ \\
\hline Spleen & $0.41 \pm 0.18$ & $0.49 \pm 0.07$ & $0.47 \pm 0.07$ & $0.49 \pm 0.05$ \\
\hline Lungs & $1.09 \pm 0.23$ & $1.17 \pm 0.13$ & $1.16 \pm 0.18$ & $1.12 \pm 0.2$ \\
\hline Heart & $0.49 \pm 0.22$ & $0.57 \pm 0.06$ & $0.57 \pm 0.06$ & $0.6 \pm 0.04$ \\
\hline Kidneys & $1.73 \pm 0.77$ & $1.97 \pm 0.08$ & $2.07 \pm 0.14$ & $2.05 \pm 0.07$ \\
\hline Testes & $0.8 \pm 0.36$ & $0.89 \pm 0.13$ & $0.9 \pm 0.18$ & $0.85 \pm 0.12$ \\
\hline Brain & $1.19 \pm 0.15$ & $1.23 \pm 0.17$ & $1.18 \pm 0.20$ & $1.26 \pm 0.18$ \\
\hline
\end{tabular}

to determine the catalytic activity of CYP3A, as described previously (Kitada et al., 1988). Reaction mixture containing $1 \mathrm{mg}$ of microsomal protein and $0.45 \mathrm{ml}$ erythromycin buffer [0.1 M phosphate buffer (pH 7.4), $0.1 \mathrm{mM}$ EDTA, and $0.4 \mathrm{mM}$ erythromycin] was prepared and incubated for 2 minutes at $37^{\circ} \mathrm{C}$ in a shaking water bath. The reaction was initiated by addition of $0.05 \mathrm{ml}$ of $50 \mathrm{mM}$ NADPH. After 30 minutes, $0.33 \mathrm{ml}$ of $15 \%$ zinc sulfate was added and was incubated for 5 minutes at room temperature. Next, $0.33 \mathrm{ml}$ of saturated barium hydroxide was added and was further incubated for 5 minutes. The samples were then centrifuged for 10 minutes. In all, $0.83 \mathrm{ml}$ of supernatant was added to $0.33 \mathrm{ml}$ of Nash reagent (30\% ammonium acetate and $0.4 \%$ acetyl acetone). The samples were then incubated for 30 minutes at $60^{\circ} \mathrm{C}$ and centrifuged, and absorbance of supernatant was measured on visible spectrophotometer at $415 \mathrm{~nm}$. Catalytic activity of CYP3A was calculated and expressed in nanomoles per milligram per minute.

Statistical Analysis. Tumor volume was analyzed using a twoway ANOVA mixed effect coupled with a Tukey post hoc test, with a day of treatment as a repeated-measures factor and drug treatment as an independent factor. All other data that were independent of time were analyzed using a one-way ANOVA coupled with Bonferroni post hoc test. Data are presented as means \pm S.D. $P<0.05$ was the minimal requirement for a statistically significant difference. Data were tested for normality using the Kolmogorov-Smirnov test, and non-normal data were log-transformed before further analysis.

\section{Results}

Combination of Crizotinib and Selumetinib Enhanced Antitumor Effect in an ALK-Positive NSCLC Xenograft Mouse Model. Orally administered crizotinib $(25 \mathrm{mg} / \mathrm{kg})$, selumetinib $(25 \mathrm{mg} / \mathrm{kg})$, and their combination were administered daily by oral gavage for 14 days in $\mathrm{Nu} / \mathrm{J}$ mice bearing H3122 xenografts. There were slight decreases in the body weight of the mice in all four groups (Table 1), but there was no statistically significant difference in body weight between treatment groups and vehicle control. Similarly, we found no significant differences in organ weight (expressed as percentage of body weight) among the treatment groups compared with vehicle control (Table 1 ).

Crizotinib, selumetinib, and their combination treatment significantly decreased tumor volume by $52 \%, 59 \%$, and $76 \%$ compared with control. Combination treatment showed significant decreases in tumor volume (76\%) compared with the crizotinib (52\%, $P<0.0001$, two-way ANOVA) and the selumetinib (56\%, $P<0.05$, two-way ANOVA) single-drug treatments. Of particular note, unexpectedly, mice treated with selumetinib alone had decreased tumor growth similar to that for crizotinib alone (Fig. 1).
Neoplastic histology was confirmed by Ki67 immunolabeling (Fig. 2A). Ki67 is a marker of proliferating cells, and $60 \%-70 \%$ of cells in tumors from all treatment groups were Ki67-positive. Because selumetinib alone suppressed tumor growth more than the ALK inhibitor crizotinib, we hypothesized that a possible mechanism that could explain this could be inhibition of angiogenesis by interference with extracellular receptor kinase (ERK) signaling (Murphy et al., 2006). We therefore carried out immunohistochemistry for CD105, an endothelial cell marker. However, all tumors from all treatment groups were well vascularized, as visualized with CD105 staining, with no statistically significant difference in MVD among the treatment groups and vehicle control (Fig. 2C, $P>0.05$, one-way ANOVA).

We then hypothesized that the frequency of apoptotic cells would be greatest in the treatment groups with the greatest tumor suppression (i.e., selumetinib alone and crizotinib plus selumetinib combination). However, histologic staining for apoptosis using TUNEL unexpectedly revealed that the highest frequency of apoptotic cells was in tumors from

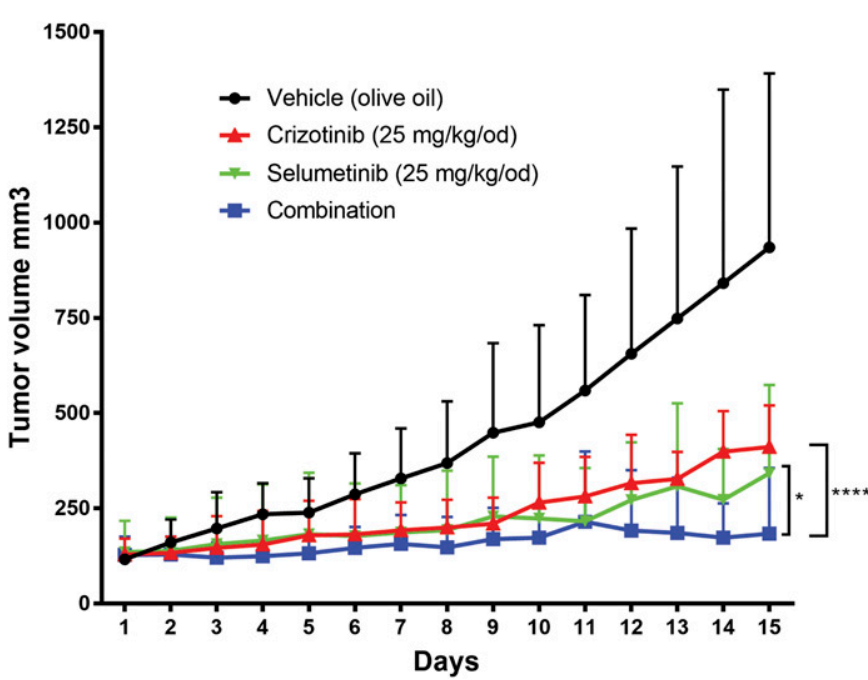

Fig. 1. Combination of crizotinib and selumetinib significantly suppresses tumor volume compared with single-drug treatment in a mouse xenograft model of H3122 lung adenocarcinoma. H3122 xenograft mice were orally administered with a vehicle (olive oil), crizotinib $(25 \mathrm{mg} / \mathrm{kg}$ ), selumetinib $(25 \mathrm{mg} / \mathrm{kg})$, and their combination daily for 2 weeks. Significance was determined by mixed-model two-way ANOVA with Tukey post hoc tests. All data are presented as means \pm S.D. from $n=7$. Statistical differences between the growth curves as a whole are indicated with asterisks; $* P<0.05 ; * * * * P<0.0001$. 
TUNEL

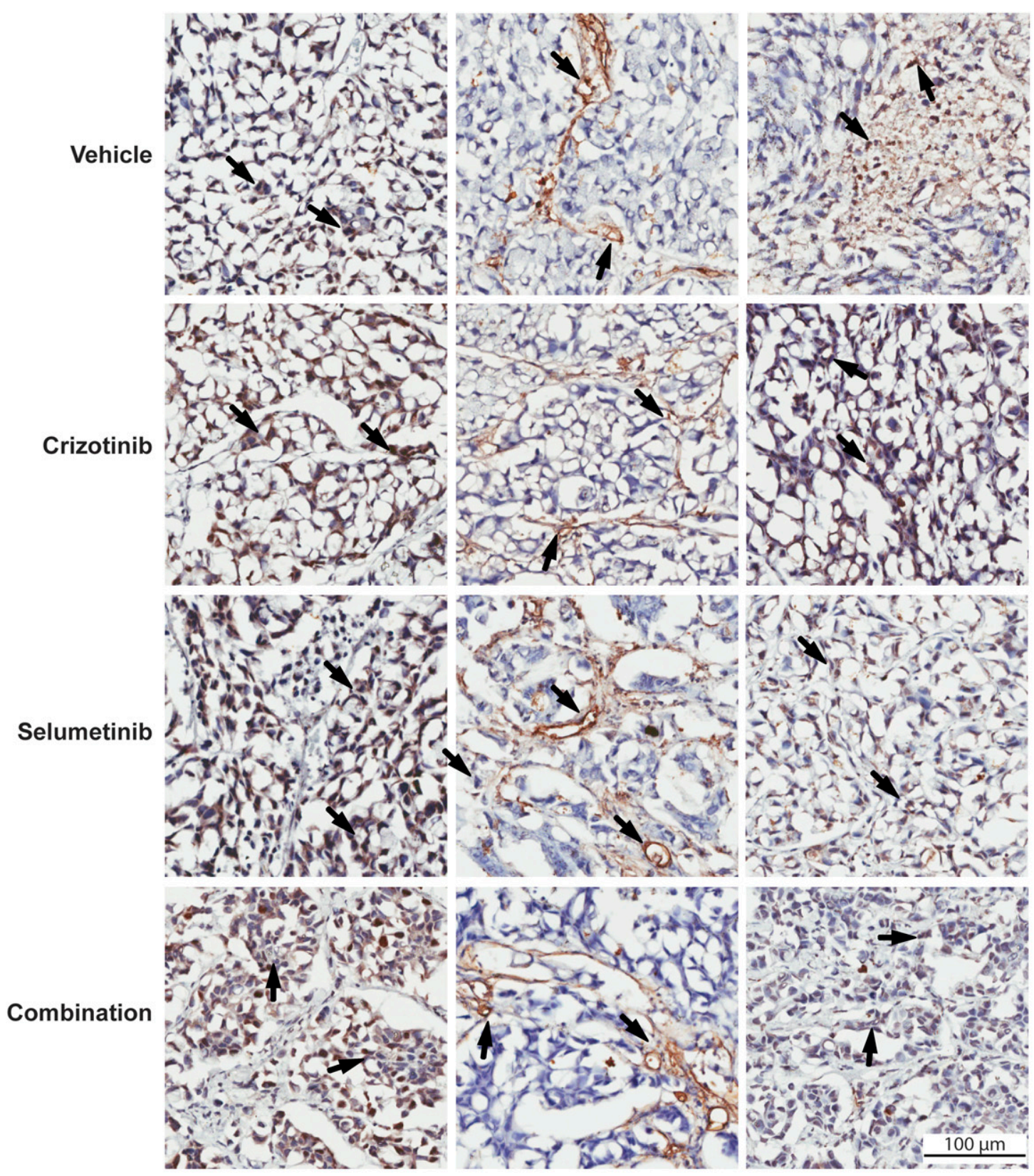

B

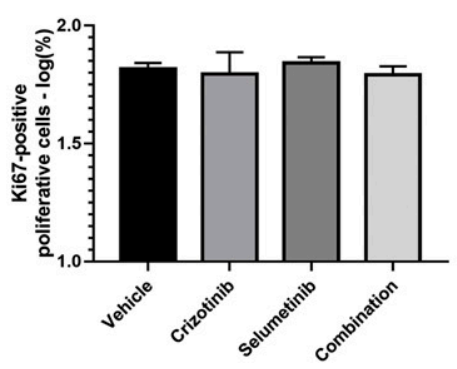

C

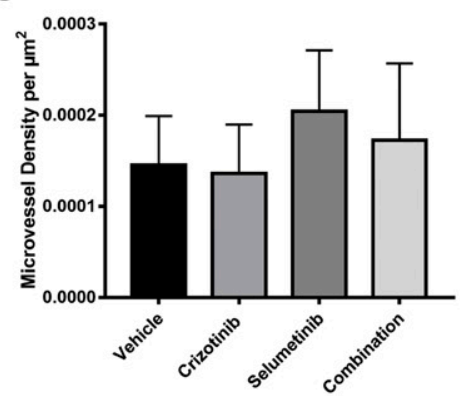

D

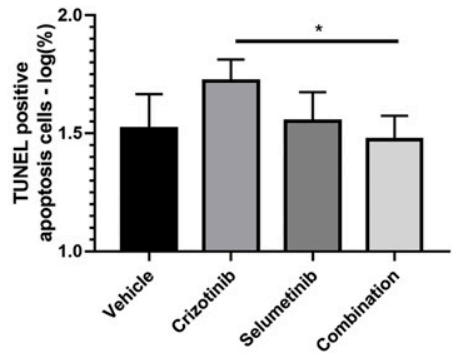

Fig. 2. Effect of combination treatment on markers of cell proliferation, apoptosis, and angiogenesis. The H3122 xenograft mice were orally gavaged daily with vehicle (olive oil), crizotinib $(25 \mathrm{mg} / \mathrm{kg})$, selumetinib $(25 \mathrm{mg} / \mathrm{kg})$, and their combination for 2 weeks. Tumors were resected and analyzed by IHC. (A) Representative IHC staining of Ki67 (first column), CD105 (middle column), and TUNEL (last column). (B) Quantification of Ki67-positive cells using IHC nuclear image algorithm. (C) Quantification of TUNEL-positive cells using IHC nuclear image algorithm. (D) Quantification of CD105positive endothelial cells using microvessel algorithm. Significance was determined by one-way ANOVA with Bonferroni post hoc tests. All data are presented as means \pm S.D. from $n=5$. Multiple comparison among treatment groups and vehicle did not show a significant difference in Ki67, CD105, and TUNEL staining ( $* P>0.05)$. Scale bar, $100 \mu \mathrm{m}$. IHC, immunohistochemistry. 
crizotinib-treated mice. By contrast, tumors from mice treated for 14 days with selumetinib either alone or in combination with crizotinib did not show a significantly different frequency of apoptotic cells compared with control mice (Fig. 2B, $P>0.05$, one-way ANOVA).

Preclinical Toxicity of Crizotinib and Selumetinib Singular and Combination Treatment. To further investigate the potential drug-induced toxicity of crizotinib, selumetinib, and their combination, we treated BALB/c mice with the vehicle (DMSO/olive oil, $5 \mathrm{ml} / \mathrm{kg}$ ), crizotinib (25 $\mathrm{mg} / \mathrm{kg}$ ), selumetinib (25 $\mathrm{mg} / \mathrm{kg}$ ), and their respective combination orally once daily for 14 days. Change in body weight was not significantly different between the treatment groups (Supplemental Table 1). Furthermore, there was no significant difference in organ weight between treatment groups and vehicle control for all major organs (Supplemental Table 1).

Next, to determine the effect of drugs on kidney and liver function, we measured plasma for ALT activity and creatinine levels. ALT activity in treatment groups was not significantly different from vehicle control. However, one mouse from the vehicle- and crizotinib-treated groups had ALT activity levels greater than $80 \mathrm{U} / \mathrm{l}$ (i.e., 126 and $89 \mathrm{U} /$, respectively, Fig. 3A). We further explored the histopathology of liver section by performing H\&E staining. We found no histopathological differences in liver sections between treatment groups and vehicle control. We did not find necrotic cells or lesions in liver section from vehicle or drug treatment groups (Supplemental Fig. 2). Moreover, there was no significant difference in creatinine level (a kidney function marker) between any of the treatment groups, as all mice had plasma creatinine values in the normal range $(<2 \mathrm{mg} / \mathrm{dl})$ (Fig. 3B).

Combination of Crizotinib and Selumetinib Does Not Alter CYP3A Activity In Vivo. We investigated whether crizotinib and selumetinib alone and in combination could alter activity of their major metabolizing enzyme, CYP3A. There was no significant change in CYP3A catalytic activity in single or combination treatment of crizotinib and selumetinib compared with vehicle control. Used as a positive control to check on assay validity, dexamethasone, a CYP3A inducer, significantly increased CYP3A catalytic activity compared with vehicle control ( $P<0.0001$, one-way ANOVA) (Fig. 4A).

A

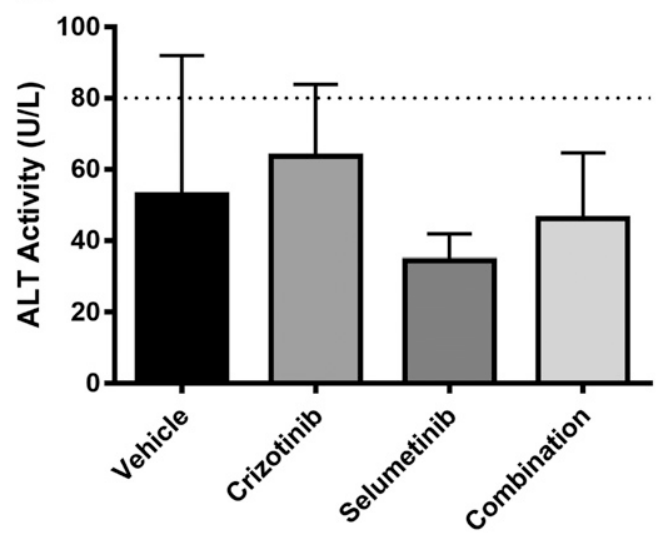

Furthermore, Western blotting of microsomal protein showed no change in polypeptide levels of hepatic CYP3A by crizotinib, selumetinib, or their combination (Fig. 3B). Again, we observed a significant increase in CYP3A protein by dexamethasone compared with control (Fig. 3C) $(P<0.0001$, oneway ANOVA). These results suggest that neither crizotinib $(25 \mathrm{mg} / \mathrm{kg})$ nor selumetinib $(25 \mathrm{mg} / \mathrm{kg})$ nor a combination of the two alter the metabolism of either drug.

\section{Discussion}

We initially aimed to test the hypothesis that the combination of the MEK inhibitor selumetinib with the ALK inhibitor crizotinib would reduce tumor growth in a mouse model of ALK-positive NSCLC to a greater extent than crizotinib alone. In a previous study, the ALK and MEK inhibitors ceritinib and trametinib had been found to have such an effect (Hrustanovic et al., 2015). Moreover, we had previously found that the addition of selumetinib to crizotinib in cell-based assays profoundly suppressed ALK-positive cancer cell growth (Shrestha et al., 2019). In addition, the drug combination strongly suppressed ERK activation along with activation of downstream mediators of cell proliferation and induction of mediators of apoptosis. Here, we indeed found that the addition of selumetinib to crizotinib greatly reduced tumor growth compared with crizotinib alone (Fig. 1). However, unexpectedly, selumetinib alone reduced tumor growth almost to the same degree as the drug combination.

The difference between our results and those of Hrustonavic et al. can be explained by dose; trametinib and selumetinib are similar in potency as MEK1 inhibitors (Wu and Park, 2015), but whereas Hrustonavic et al. administered $1 \mathrm{mg} / \mathrm{kg}$ per day of trametinib, in the present study, we administered $25 \mathrm{mg} / \mathrm{kg}$ per day of selumetinib. Nevertheless, the unexpected efficacy of selumetinib as a monotherapy in vivo does not support the hypothesis that dual MEK/ALK inhibition in ALK-positive cancer would add benefit beyond what could be achieved by a sufficient dose of an MEK inhibitor alone. This conclusion is supported by our toxicology results. Several studies have shown that both the crizotinib and selumetinib single-drug treatments can induce adverse events that range from grade 1-2 to grade 3-4 (Camidge et al., 2012; Catalanotti et al., 2013;

\section{B}

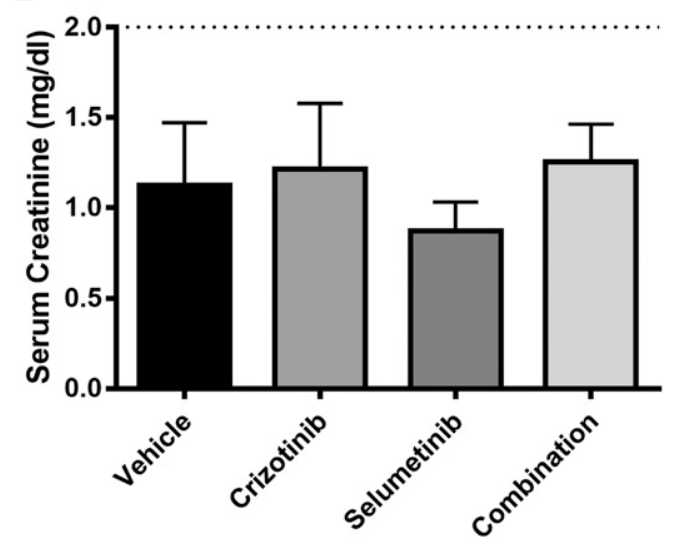

Fig. 3. Effect of crizotinib, selumetinib, and their combination on liver and kidney function in BALB/c mice. (A) ALT activity. (B) Plasma creatinine levels after treatment with vehicle ( $25 \% \mathrm{DMSO} / \mathrm{olive}$ oil), crizotinib $(25 \mathrm{mg} / \mathrm{kg}$ daily), selumetinib ( $25 \mathrm{mg} / \mathrm{kg}$ daily), and their combination for $2 \mathrm{weeks}$. Significance was determined by one-way ANOVA with Bonferroni post hoc test. All data are presented as means \pm S.D. None were significantly different. 
A

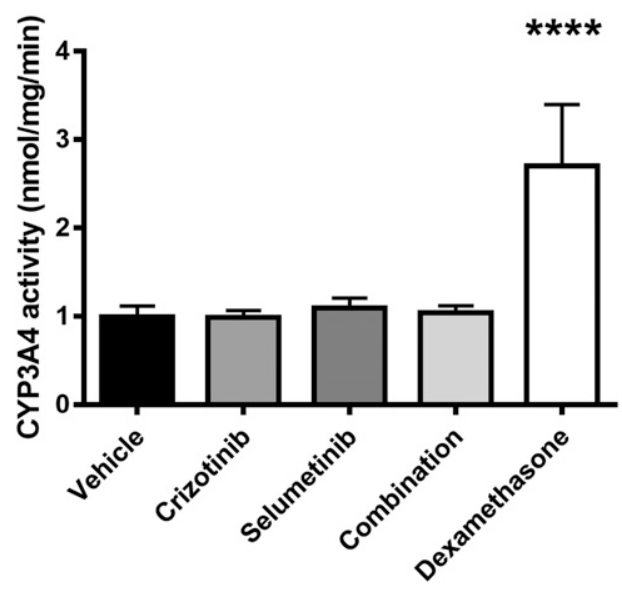

B

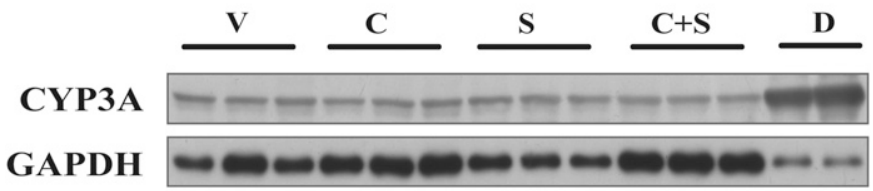

C

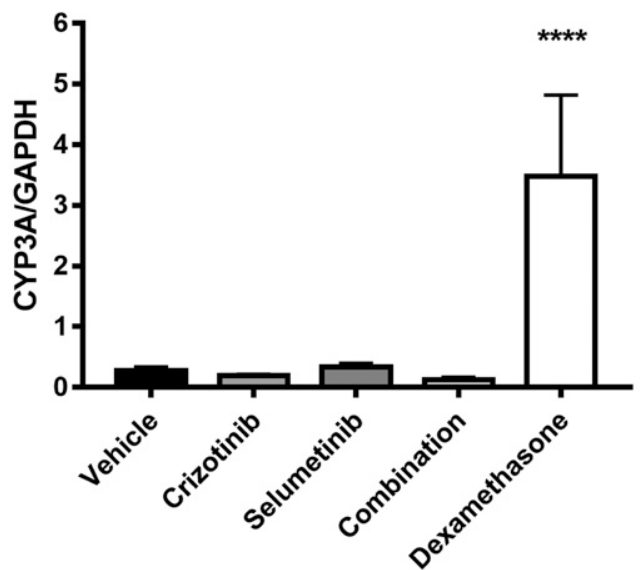

Fig. 4. Crizotinib and selumetinib alone or in combination do not modulate CYP3A polypeptide levels or catalytic activity. BALB/c mice were orally gavaged daily with vehicle (25\% DMSO/olive oil), crizotinib $(25 \mathrm{mg} / \mathrm{kg})$, selumetinib $(25 \mathrm{mg} / \mathrm{kg})$, and their combination for 2 weeks. Liver was harvested, and microsomes were prepared. (A) CYP3A catalytic activity. (B) Representative Western blots of CYP3A. (C) Densitometry of Western blots of CYP3A. (C) Densitometry of Western blots of CYP3A. Significance was determined by one-way ANOVA with Bonferroni post hoc test. All data are presented as means \pm S.D. $* * * * P<0.0001$. C, crizotinib; $\mathrm{C}+\mathrm{S}$, combination; D, dexamethasone; GAPDH, glyceraldehyde-3-phosphate dehydrogenase; S, selumetinib; V, vehicle.

Carvajal et al., 2014). But in this study, $25 \mathrm{mg} / \mathrm{kg}$ per day of selumetinib did not elevate any of the measures of toxicity, so results comparable to combination drug treatment may be achieved by an MEK inhibitor alone at a tolerable dose.

Our results here are also in contrast to the results of our previously published in vitro experiments using H3122 cells, in which selumetinib alone was 30 -fold less potent at reducing cell viability than crizotinib alone (Shrestha et al., 2019). The reasons for the difference between these in vitro and in vivo results are unclear. The bioavailability of crizotinib (49\%)
(Kwon and Meagher, 2012) is only slightly less than that of selumetinib (62\%) (Dymond et al., 2016), an insufficient difference to explain the contrast between the results we obtained in vitro previously and in vivo in this study. We considered that possible differences in drug metabolism may help explain the results. Crizotinib is the primary substrate of CYP3A and, according to in vitro studies, causes moderate CYP3A protein inhibition and induces mRNA expression (Tan et al., 2010; Mao et al., 2013; Johnson et al., 2015). CYP3A4 is also the major enzyme responsible for selumetinib metabolism (Dymond et al., 2016). We hypothesized then that CYP3A activity could be greater in mice treated with crizotinib, reducing crizotinib exposure compared with selumetinib administered alone. Nevertheless, we did not detect any differences in either hepatic CYP3A activity or polypeptide levels between crizotinib, selumetinib, or their combination compared with controls.

We carried out immunolabeling studies in a further attempt to determine the reasons for the unexpected efficacy of selumetinib as a monotherapy in this study. Both selumetinib and crizotinib are known to have antitumor activity by increasing apoptosis and decreasing cell proliferation and angiogenesis. We first hypothesized that selumetinib may have had an antiangiogenic effect through suppression of ERK activation (Murphy et al., 2006). Contrary to this hypothesis, both single and combination treatments did not reduce MVD in tumors taken from mice at day 14 compared with control as measured by CD105 immunolabeling (Fig. 2C). We then hypothesized that the selumetinibtreated tumors would show increased frequency of apoptosis. Contrary to this hypothesis, apoptosis was upregulated only in the crizotinib group compared with control (Fig. 2D). Finally, we hypothesized a cytostatic effect for selumetinib, but in contradiction to this, there were no differences in proliferating cell frequency as measured by Ki67 immunolabeling (Fig. 2B).

Our in vitro study had demonstrated that crizotinib, selumetinib, and their combination significantly increased G1 phase arrest using flow cytometry (Shrestha et al., 2019). However, Ki67 is present in G1, S, G2, and the mitotic phase and only absent in the G0 phase of the cell cycle (Guillaud et al., 1989; Bruno and Darzynkiewicz, 1992). Therefore, Ki67 labeling may not accurately reflect the response to treatment, as it would not differentiate between cells in G1 arrest and other cells. Furthermore, in breast cancer clinical trials, the predictive value of Ki67 as an indicator of chemotherapy benefit remains controversial, as some trials reported that Ki67 was not related to treatment outcome (International Breast Cancer Study Group (IBCSG), 2002; Viale et al., 2008; Yerushalmi et al., 2010; Martey et al., 2017, 2019). Thus, Ki67 as an independent prognostic factor does not always reflect the response to treatment. Moreover, we have shown in a xenograft model of triple negative breast cancer that Ki67 in tumor slices from treated mice was unchanged compared with control when analyzed by univariate statistical analysis (Martey et al., 2017) even though significant tumor suppression was observed. However, when multivariate analysis was performed, Ki67 played an important role, as it was part of a biologic network of 16 molecular targets that together predicted treatment outcome with a 95\% success rate (Martey et al., 2019) Therefore, it is possible that Ki67 also contributes to a larger protein network in the suppression of H3122 xenograft tumors.

Suppression of ERK activation is also known to stimulate T-cell activation in some cancers (Ebert et al., 2016). It is 
highly unlikely that this could account for our results, as the xenograft model employed athymic mice.

Further studies are needed to ascertain the translatability of these findings to humans (Nair et al., 2018). Since beginning these studies, recruitment has started for a clinical trial investigating the use of trametinib with ceritinib in ALK-positive NSCLC (https://clinicaltrials.ucsf.edu/ trial/NCT03087448), but there are no trials to our knowledge investigating selumetinib in similar patients. We used H3122 cells, as they contain the most common ELM4-ALK variant (variant 1), which is highly sensitive to ALK inhibitors (particularly to crizotinib) (Cha et al., 2016; Wilson et al., 2017). Cells modeling other less common ELM4-ALK variants, although less clinically relevant, could be tested to ascertain whether these results are applicable to other forms of lung cancer.

\section{Acknowledgments}

We would like to thank Mhairi Nimick from Department of Pharmacology and Toxicology for her technical support during development of the xenograft model.

\section{Authorship Contributions}

Participated in research design: Shrestha, Rosengren, Ashton.

Conducted experiments: Shrestha, Bland, Bower.

Performed data analysis: Shrestha, Ashton.

Wrote or contributed to writing of the manuscript: Shrestha, Rosengren, Ashton.

\section{References}

Bruno S and Darzynkiewicz Z (1992) Cell cycle dependent expression and stability of the nuclear protein detected by Ki-67 antibody in HL-60 cells. Cell Prolif 25:31-40.

Camidge DR, Bang YJ, Kwak EL, Iafrate AJ, Varella-Garcia M, Fox SB, Riely GJ, Solomon B, Ou SHI, Kim DW, et al. (2012) Activity and safety of crizotinib in patients with ALK-positive non-small-cell lung cancer: updated results from a phase 1 study. Lancet Oncol 13:1011-1019.

Carvajal RD, Sosman JA, Quevedo JF, Milhem MM, Joshua AM, Kudchadkar RR, Linette GP, Gajewski TF, Lutzky J, Lawson DH, et al. (2014) Effect of selumetinib vs chemotherapy on progression-free survival in uveal melanoma: a randomized clinical trial. JAMA 311:2397-2405.

Catalanotti F, Solit DB, Pulitzer MP, Berger MF, Scott SN, Iyriboz T, Lacouture ME, Panageas KS, Wolchok JD, Carvajal RD, et al. (2013) Phase II trial of MEK inhibitor selumetinib (AZD6244, ARRY-142886) in patients with BRAFV600E/K-mutated melanoma. Clin Cancer Res 19:2257-2264.

Cha YJ, Kim HR, and Shim HS (2016) Clinical outcomes in ALK-rearranged lung adenocarcinomas according to ALK fusion variants. J Transl Med 14:296.

Choi YL, Soda M, Yamashita Y, Ueno T, Takashima J, Nakajima T, Yatabe Y, Takeuchi K, Hamada T, Haruta H, et al.; ALK Lung Cancer Study Group (2010) EML4-ALK mutations in lung cancer that confer resistance to ALK inhibitors N Engl J Med 363:1734-1739.

Doebele RC, Pilling AB, Aisner DL, Kutateladze TG, Le AT, Weickhardt AJ, Kondo KL, Linderman DJ, Heasley LE, Franklin WA, et al. (2012) Mechanisms of resistance to crizotinib in patients with ALK gene rearranged non-small cell lung cancer. Clin Cancer Res 18:1472-1482.

Dymond AW, Howes C, Pattison C, So K, Mariani G, Savage M, Mair S, Ford G, and Martin P (2016) Metabolism, excretion, and pharmacokinetics of selumetinib, an MEK1/2 inhibitor, in healthy adult male subjects. Clin Ther 38:2447-2458.

Ebert PJR, Cheung J, Yang Y, McNamara E, Hong R, Moskalenko M, Gould SE, Maecker $\mathrm{H}$, Irving BA, Kim JM, et al. (2016) MAP kinase inhibition promotes T cell and antitumor activity in combination with PD-L1 checkpoint blockade. Immunity 44:609-621.

Ettinger DS, Akerley W, Borghaei H, Chang AC, Cheney RT, Chirieac LR, D'Amico TA, Demmy TL, Govindan R, Grannis FW Jr, et al. National comprehensive cancer network (2013) Non-small cell lung cancer, version 2.2013. J Natl Compr Canc Netw 11:645-653, quiz 653

Ferlay J, Soerjomataram I, Dikshit R, Eser S, Mathers C, Rebelo M, Parkin DM Forman D, and Bray F (2015) Cancer incidence and mortality worldwide: sources, methods and major patterns in GLOBOCAN 2012. Int J Cancer 136:E359-E386.

Guengerich PF (2014) Analysis and characterization of enzymes and nucleic acids relevant to toxicology, in Hayes' Principles and Methods of Toxicology (Hayes AW and Kruger CL eds) 6th ed, pp 1905-1964, Taylor \& Francis, Abingdon, UK.

Guillaud P, du Manoir S, and Seigneurin D (1989) Quantification and topographical description of Ki-67 antibody labelling during the cell cycle of normal fibroblastic (MRC-5) and mammary tumour cell lines (MCF-7). Anal Cell Pathol 1:25-39.

Hrustanovic G, Olivas V, Pazarentzos E, Tulpule A, Asthana S, Blakely CM, Okimoto RA Lin L, Neel DS, Sabnis A, et al. (2015) RAS-MAPK dependence underlies a rational polytherapy strategy in EML4-ALK-positive lung cancer. Nat Med 21:1038-1047.

International Breast Cancer Study Group (IBCSG) (2002) Endocrine responsiveness and tailoring adjuvant therapy for postmenopausal lymph node-negative breast cancer: a randomized trial [published correction appears in $J$ Natl Cancer Inst (2002) 94:1339]. J Natl Cancer Inst, 94:1054-1065.

Johnson TR, Tan W, Goulet L, Smith EB, Yamazaki S, Walker GS, O'Gorman MT, Bedarida G, Zou HY, Christensen JG, et al. (2015) Metabolism, excretion and pharmacokinetics of [14C]crizotinib following oral administration to healthy subjects. Xenobiotica 45:45-59.

Katayama R, Shaw AT, Khan TM, Mino-Kenudson M, Solomon BJ, Halmos B, Jessop NA, Wain JC, Yeo AT, Benes, et al. (2012) Mechanisms of acquired crizotinib resistance in ALK-rearranged lung cancers. Sci Transl Med 4:120ra117.

Kazandjian D, Blumenthal GM, Chen HY, He K, Patel M, Justice R, Keegan P, and Pazdur R (2014) FDA approval summary: crizotinib for the treatment of metastatic non-small cell lung cancer with anaplastic lymphoma kinase rearrangements. Oncologist 19:e5-e11.

Kitada M, Igoshi N, Kamataki T, Itahashi K, Imaoka S, Komori M, Funae Y, Rikihisa T, and Kanakubo Y (1988) Immunochemical similarity of P-450 HFLa, a form of cytochrome P-450 in human fetal livers, to a form of rat liver cytochrome P-450 inducible by macrolide antibiotics. Arch Biochem Biophys 264:61-66.

Kwak EL, Bang Y-J, Camidge DR, Shaw AT, Solomon B, Maki RG, Ou S-HI, Dezube BJ, Jänne PA, Costa DB, et al. (2010) Anaplastic lymphoma kinase inhibition in nonsmall-cell lung cancer. N Engl J Med 363:1693-1703.

Kwak EL, Camidge D, Clark J, Shapiro G, Maki R, Ratain M, Solomon B, Bang Y, Ou $\mathrm{S}$, and Salgia R (2009) G6 Clinical activity observed in a phase I dose escalation trial of an oral c-met and ALK inhibitor, PF-02341066. Eur J Cancer 7:8.

Kwon J and Meagher A (2012) Crizotinib: a breakthrough for targeted therapies in lung cancer. $J$ Adv Pract Oncol 3:267-272.

Mao J, Johnson TR, Shen Z, and Yamazaki S (2013) Prediction of crizotinib-midazolam interaction using the Simcyp population-based simulator: comparison of CYP3A time-dependent inhibition between human liver microsomes versus hepatocytes. Drug Metab Dispos 41:343-352.

Martey O, Nimick M, Taurin S, Sundararajan V, Greish K, and Rosengren RJ (2017) Styrene maleic acid-encapsulated RL71 micelles suppress tumor growth in a murine xenograft model of triple negative breast cancer. Int J Nanomedicine 12:7225-7237.

Martey ONK, Greish K, Smith PF, and Rosengren RJ (2019) A multivariate statistical analysis of the effects of styrene maleic acid encapsulated RL71 in a xenograft model of triple negative breast cancer. J Biol Methods 6:e121.

Murphy DA, Makonnen S, Lassoued W, Feldman MD, Carter C, and Lee WM (2006) Inhibition of tumor endothelial ERK activation, angiogenesis, and tumor growth by sorafenib (BAY43-9006). Am J Pathol 169:1875-1885.

Nair A, Morsy MA, and Jacob S (2018) Dose translation between laboratory animals and human in preclinical and clinical phases of drug development. Drug Dev Res DOI: 10.1002/ddr.21461 [published ahead of print]

Nencioni A, Caffa I, Raffaghello L, Montecucco F, Cea M, Monacelli F, Grossi F, Patrone F, Odetti P, Ballestrero A, et al. (2014) Potentiation of crizotinib activity by fasting cycles in an ALK+ lung cancer model. J Clin Oncol 32:e13511.

Perner S, Wagner PL, Demichelis F, Mehra R, Lafargue CJ, Moss BJ, Arbogast S, Soltermann A, Weder W, Giordano TJ, et al. (2008) EML4-ALK fusion lung cancer: a rare acquired event. Neoplasia 10:298-302.

Roskoski R Jr (2013) Anaplastic lymphoma kinase (ALK): structure, oncogenic activation, and pharmacological inhibition. Pharmacol Res 68:68-94.

Sasaki T, Koivunen J, Ogino A, Yanagita M, Nikiforow S, Zheng W, Lathan C, Marcoux JP, Du J, Okuda K, et al. (2011) A novel ALK secondary mutation and EGFR signaling cause resistance to ALK kinase inhibitors. Cancer Res 71:6051-6060.

Shrestha N, Nimick M, Dass P, Rosengren RJ, and Ashton JC (2019) Mechanisms of suppression of cell growth by dual inhibition of ALK and MEK in ALK-positive nonsmall cell lung cancer. Sci Rep 9:18842.

Soda M, Choi YL, Enomoto M, Takada S, Yamashita Y, Ishikawa S, Fujiwara S, Watanabe H, Kurashina K, Hatanaka H, et al. (2007) Identification of the transforming EML4-ALK fusion gene in non-small-cell lung cancer. Nature 448:561-566. Solomon BJ, Mok T, Kim D-W, Wu Y-L, Nakagawa K, Mekhail T, Felip E, Cappuzzo F, Paolini J, Usari T, et al.; PROFILE 1014 Investigators (2014) First-line crizotinib versus chemotherapy in ALK-positive lung cancer. N Engl J Med 371:2167-2177.

Tan W, Wilner KD, Bang Y, Kwak EL, Maki RG, Camidge DR, Solomon BJ, Ou SI, Salgia R, and Clark JW (2010) Pharmacokinetics (PK) of PF-02341066, a dual ALK MET inhibitor after multiple oral doses to advanced cancer patients. $J$ Clin Oncol 28:2596.

Viale G, Regan MM, Mastropasqua MG, Maffini F, Maiorano E, Colleoni M, Price KN, Golouh R, Perin T, Brown RW, et al.; International Breast Cancer Study Group (2008) Predictive value of tumor Ki-67 expression in two randomized trials of adjuvant chemoendocrine therapy for node-negative breast cancer. J Natl Cancer Inst 100:207-212.

Wilson C, Nimick M, Nehoff H, and Ashton JC (2017) ALK and IGF-1R as independent targets in crizotinib resistant lung cancer. Sci Rep 7:13955.

Wu PK and Park JI (2015) MEK1/2 inhibitors: molecular activity and resistance mechanisms. Semin Oncol 42:849-862.

Yerushalmi R, Woods R, Ravdin PM, Hayes MM, and Gelmon KA (2010) Ki67 in breast cancer: prognostic and predictive potential. Lancet Oncol 11:174-183.

Zhang S, Wang F, Keats J, Zhu X, Ning Y, Wardwell SD, Moran L, Mohemmad QK, Anjum R, Wang Y, et al. (2011) Crizotinib-resistant mutants of EML4-ALK identified through an accelerated mutagenesis screen. Chem Biol Drug Des 78:999-1005. Zhou WJ, Zhang X, Cheng C, Wang F, Wang XK, Liang YJ, To KKW, Zhou W, Huang $\mathrm{HB}$, and Fu LW (2012) Crizotinib (PF-02341066) reverses multidrug resistance in cancer cells by inhibiting the function of P-glycoprotein. $\mathrm{Br} J$ Pharmacol 166: 1669-1683.

Address correspondence to: J.C. Ashton, Department of Pharmacology and Toxicology, School of Biomedical Sciences, University of Otago, Dunedin, Ot 9016, New Zealand. E-mail: john.ashton@otago.ac.nz 